\title{
Population history associated with hydrothermal vent activity inferred from genetic structure of neoverrucid barnacles around Japan
}

\author{
Hiromi Watanabe ${ }^{1, *}$, Shinji Tsuchida ${ }^{2}$, Katsunori Fujikura $^{2}$, Hiroyuki Yamamoto ${ }^{2}$, \\ Fumio Inagaki $^{2}$, Masanori Kyo ${ }^{2}$, Shigeaki Kojima ${ }^{1}$ \\ ${ }^{1}$ Ocean Research Institute, University of Tokyo, 1-15-1 Minamidai, Nakano, Tokyo 164-8639, Japan \\ ${ }^{2}$ Japan Agency for Marine-Earth Science and Technology, 2-15 Natsushima-cho, Yokosuka, Kanagawa 237-0061, Japan
}

\begin{abstract}
The population histories of neoverrucid barnacles occurring at 2 different hydrothermal vent systems around Japan, namely the Izu-Ogasawara Arc and the Okinawa Trough, were investigated based on the sequence variation in a $661 \mathrm{bp}$ fragment of the mitochondrial COI gene. Compared with other barnacles, the investigated neoverrucids showed low levels of genetic diversity. The mismatch analysis suggested that these neoverrucids have experienced extinction-recolonization events associated with vent activity, and this may have led to the low levels of genetic diversity in neoverrucids around Japan. No haplotypes were shared between the Izu-Ogasawara Arc and the Okinawa Trough and no significant genetic differences were detected among the populations within each of these 2 regions. These results suggest that neoverrucid larvae only disperse within each area and are unable to migrate between the 2 areas. The haplotypes of the Okinawa Trough formed a paraphyletic cluster, with the exclusion of a monophyletic cluster from the Izu-Ogasawara Arc. Furthermore, the population expansion date of the Okinawa Trough, as estimated from the mismatch analysis, was earlier than that of the Izu-Ogasawara Arc. These results suggested that the neoverrucid population in the Okinawa Trough was a source of neoverrucids inhabiting the Izu-Ogasawara Arc.
\end{abstract}

KEY WORDS: Neoverrucidae $\cdot$ Barnacle $\cdot$ Population structure $\cdot$ Dispersal $\cdot$ Hydrothermal activity

\section{INTRODUCTION}

Biological communities associated with hydrothermal vents contain many endemic species (Tunnicliffe \& Fowler 1996). Vent fields are discretely distributed and individual vents are thought to be ephemeral (Newman 1985, Holm \& Hennet 1992). Therefore, how ventendemic animals disperse and evolve is an interesting issue. For vent-endemic sessile organisms, their planktonic period (larvae or gametes) is the most plausible opportunity for migration leading to gene flow from vent to vent and from one vent field to another.

Around Japan, different types of hydrothermal vent fields have been found in the 2 major oceanic areas to the south of the main archipelago, namely, the IzuOgasawra (Bonin) Island Arc, southeast of Japan, and the Okinawa Trough in the East China Sea (Ishibashi \& Urabe 1995; present Fig. 1). The volcanic activity of the Izu-Ogasawara Arc is considered to be periodic, although its history goes back to $17 \mathrm{Myr}$ (million years) ago. During the last million years, the activity has converged into a narrow area (Morita et al. 1999). The Okinawa Trough is considered to be a nascent backarc basin within the continental margin (Ishibashi \& Urabe 1995), and its activity has continued from 2 Myr ago (Furukawa 1991). The animal communities inhabiting these 2 vent fields have been described (e.g. Ohno et al. 1996); however, the population histories of each vent-endemic species have not yet been elucidated.

As well as the tectonic setting, the vent fauna of these 2 regions also differ. In the hydrothermal vent fields of the Izu-Ogasawara Arc, the mussel Bathymodiolus 


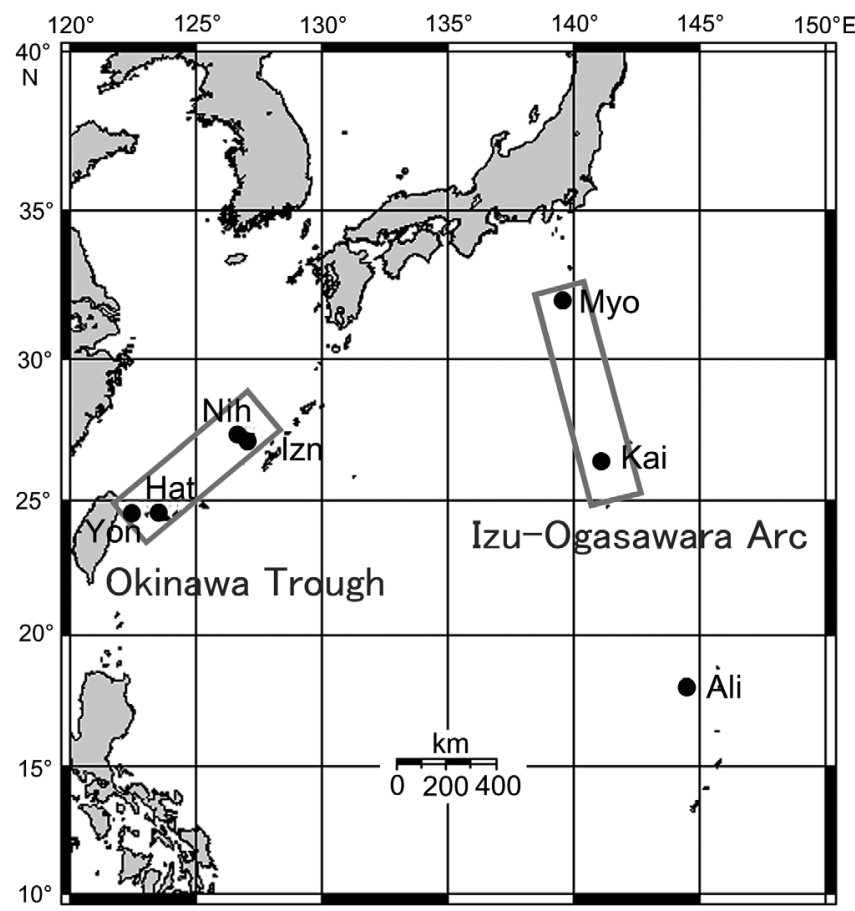

Fig. 1. Sampling sites for neoverrucids. Myo: Myojin Knoll (1200 m depth); Kai: Kaikata Seamount (450 m depth); Izn: Izena Hole (1600 m depth); Nih: North Iheya Ridge (1000 m depth); Hat: Hatoma Knoll (1500 m depth); Yon: Dai-yon (No. 4) Yonaguni Knoll (1350 m depth); Ali: Alice Spring site (3650 $\mathrm{m}$ depth). Myo and Kai are located in the IzuOgasawara Arc; Izn, Nih, Hat, and Yon in Okinawa Trough; and Ali in Mariana Trough

septemdierum and the crab Austinograea yunohana are dominant, while vent-communities in the Okinawa Trough are dominated by the mussel B. platifrons and the galatheid crab Shinkaia crosneiri (Kojima 2002). These facts suggest that migration between the IzuOgasawara Arc and the Okinawa Trough is a rare event for many vent-endemic species. A few species have been observed from both the Izu-Ogasawara Arc and the Okinawa Trough (e.g. Okutani \& Fujiwara 2000), but gene flow between these 2 regions has never been examined.

Vent-endemic barnacles belonging to the family Neoverrucidae (Newman \& Hessler 1989) should be suitable material for examination of the migration history between the Izu-Ogasawara Arc and the Okinawa Trough because they are abundant in the hydrothermal vent fields of these regions (Iizasa et al. 1999, Fujikura et al. 2001). Neoverrucids consist of the 2 genera Neoverruca Newman \& Hessler, 1989 and Imbricaverruca Newman, 2000, and the former is a common barnacle in Western Pacific vent fields. These genera at present contain only 1 described species each, Neoverruca brachylepadoformis Newman \& Hessler, 1989 and Imbricaverruca yamaguchii
Newman, 2000, respectively. The neoverrucid barnacles inhabiting both the Izu-Ogasawara Arc and the Okinawa Trough vent fields seem to be neither $N$. brachylepadoformis nor I. yamaguchii. The morphology of the Japanese forms, while variable (vestigial median latus, incomplete complement of basal imbricating plates and higher-than-wide fixed wall plates) suggested that they should be classified as a single species in the genus Neoverruca distinct from $N$. brachylepadoformis. Therefore, we treat them as Neoverruca sp. related to but genetically distinct from $N$. brachylepadoformis from the Mariana Trough.

In this study, we attempted to estimate gene flow between/within the Izu-Ogasawara Arc and the Okinawa Trough using this vent barnacle, and applied population genetic analyses to reveal their population histories associated with vent activity around Japan.

\section{MATERIALS AND METHODS}

We collected 96 neoverrucids from 6 hydrothermal vent fields around Japan using the Japanese submersible, 'Shinkai 2000', and the remotely operated vehicle (ROV) 'HyperDolphin' (Table 1). As a representative sample of neoverrucid barnacles, Neoverruca brachylepadoformis, which was collected by the 'Shinkai 6500' from the Alice Spring site in the Mariana Trough, was added to the phylogenetic analysis. As outgroups, 3 species of verrucid barnacles (Altiverruca sp., Brochiverruca sp. and Rostratoverruca krügeri) that were collected in the East China Sea by beam trawls during the KT02-03 cruise of the RV 'Tansei-Maru' were used in the phylogenetic analysis. These samples were stored in $99.5 \%$ ethanol or at $-80^{\circ} \mathrm{C}$.

Genomic DNA was extracted from the basal depressor muscle of each specimen using proteinase

Table 1. Collection data for neoverrucid specimens examined in the present study

\begin{tabular}{|lccc|}
\hline Locality & Code & $\begin{array}{c}\text { Dive } \\
\text { No. }\end{array}$ & $\begin{array}{c}\text { No. of } \\
\text { individuals }\end{array}$ \\
\hline $\begin{array}{l}\text { Izu-Ogasawara Arc } \\
\text { Myojin Knoll }\end{array}$ & Myo & 2K\#1008 & 19 \\
$\begin{array}{l}\text { Kaikata Seamount } \\
\text { Okinawa Trough }\end{array}$ & Kai & 2K\#1237, HD\#188 & 5 \\
$\begin{array}{l}\text { Izena Hole } \\
\text { North Iheya Ridge }\end{array}$ & Izn & HD\#209 & 19 \\
$\begin{array}{l}\text { Hatoma Knoll } \\
\text { Dai-yon Yonaguni Knoll }\end{array}$ & Hat & HD\#1194 & 17 \\
Mariana Trough & 2K\#1273,HD\#298 & 16 \\
Alice Spring & Ali & 6K\#185 & 20 \\
\hline
\end{tabular}


K digestion followed by phenol/chloroform extraction and ethanol precipitation or the DNeasy Tissue Extraction Kit (QIAGEN). Part (661 bp) of the mitochondrial gene for cytochrome oxidase $c$ Subunit I (COI) was amplified using the primers LCO1490 and HCO2198 designed by Folmer et al. (1994). Amplification was performed in $25 \mu \mathrm{l}$ reaction mixtures containing approximately $0.25 \mathrm{ng}$ of genomic DNA, $1 \times$ PCR buffer, $3 \mathrm{mM}$ of $\mathrm{Mg}^{2+}, 0.3 \mathrm{mM}$ of dNTP mix, $1 \mathrm{mM}$ of each primer and $0.05 \mathrm{U} \mathrm{\mu l}^{-1}$ of EX Taq DNA polymerase (TaKaRa). Reactions were carried out with an initial denaturation step at $94^{\circ} \mathrm{C}(120 \mathrm{~s})$ followed by 35 cycles consisting of a denaturation step at $94^{\circ} \mathrm{C}(60 \mathrm{~s})$, an annealing step at $50^{\circ} \mathrm{C}(40 \mathrm{~s})$, and an extension step at $72^{\circ} \mathrm{C}(90 \mathrm{~s})$.

PCR products were purified using Exo-SAP-IT (United States Biochemical). DNA sequences were obtained using an ABI 3100 automated DNA sequencer (Applied Biosystems) with a BigDye Terminator Cycle Sequencing Kit Version 3.0 (Applied Biosystems).

The forward and reverse sequences obtained were assembled into contigs with the program ATGC (Genetyx Version 6) and aligned by eye. Nucleotide diversity $(\pi)$ and haplotype diversity $(\hat{H})$ of populations were estimated with the program ARLEQUIN Version 2.000 (Schneider et al. 2000). The significance of population structure was tested by analysis of molecular variance (AMOVA; Excoffier et al. 1992) and genetic difference among populations was tested by exact tests (Raymond \& Rousset 1995) with ARLEQUIN Version 2.000 .

Rogers \& Harpending (1992) suggested that mismatch distribution (a frequency distribution of the observed number of differences between paired individuals in a population) conveyed information on the timing and the amplitude of past population expansion, i.e. populations at demographic equilibrium show multimodal distributions and populations that have passed through a recent demographic expansion show unimodal distributions. Mismatch analyses that test whether observed mismatch distributions fit a simulated sudden-expansion model (Schneider \& Excoffier 1999) were conducted with ARLEQUIN 2.000 for the populations of the Izu-Ogasawara Arc (the Myojin Knoll and the Kaikata Seamount) and those of the Okinawa Trough (Izena Hole, North Iheya Ridge, Hatoma Knoll and Dai-yon Yonaguni Knoll). If the mismatch distribution fitted to a simulated sudden-expansion model, the generation number since the population started expanding $(t)$ could be estimated from the equation $t=\tau / 2 u$, where $\tau$ is an estimate given from mismatch analysis and $u$ is the total mutation rate per generation per gene (Schneider \& Excoffier 1999). In this study, the mutation rate that was calculated by
Knowlton \& Weigt (1998) for snapping shrimp (1.4\% per million years for the mitochondrial COI gene) was used for estimating $u$.

Phylogenetic reconstruction was conducted with all sequenced haplotypes according to neighbor-joining (NJ) and maximum-parsimony (MP) criteria, using the software package MEGA Version 2.1 (Kumar et al. 2001). For reconstructing the NJ tree, Kimura 2-parameter distance was used and 1000 replicates were conducted for bootstrapping. Divergence time between haplotypes of the Izu-Ogasawara Arc and those of the Okinawa Trough was estimated using Kimura 2-parameter sequence divergence and the substitution rate estimated for snapping shrimps (Knowlton \& Weigt 1998).

\section{RESULTS}

We obtained 24 haplotypes from 96 Japanese neoverrucid specimens. The $661 \mathrm{bp}$ sequences contained 29 polymorphic sites. Nucleotide sequences obtained from the 24 haplotypes, as well as those of Neoverruca brachylepadoformis and 3 verrucid species, will appear in the GSDB, DDBJ, EMBL and NCBI nucleotide sequence databases under Accession Nos. AB195582 to AB195609.

Of the 24 haplotypes, 9 were endemic to the IzuOgasawara Arc region (the Myojin Knoll and the Kaikata Seamount) and the other 15 were endemic to the Okinawa Trough region (the Izena Hole, the North Iheya Ridge, the Hatoma Knoll and the Daiyon Yonaguni Knoll; Fig. 2). No haplotype was shared between these 2 regions. A single dominant haplotype was recognized for the Izu-Ogasawara Arc and 2 dominant haplotypes for the Okinawa Trough. All specimens from the Kaikata Seamount shared a single haplotype, which was identical to the dominant haplotype in the Myojin Knoll population, the most dominant haplotype in the Izu-Ogasawara Arc. The nucleotide diversity $(\pi)$ and haplotype diversity $(\hat{H})$ of each population and 2 regional populations (the Izu-Ogasawara Arc and the Okinawa Trough) are shown in Table 2.

The AMOVA results are shown in Table 3. No significant population subdivision was detected within the 2 areas $(p=0.784)$. The exact test also revealed that the haplotypes were distributed randomly within the 2 regions $(p>0.05)$.

The mismatch distributions for the Izu-Ogasawara Arc and the Okinawa Trough are shown in Fig. 3. The sudden-expansion model was thought to be fitted with the populations of the Izu-Ogasawara Arc and the Okinawa Trough. The estimated $\tau$ is also shown in Fig. 3. The generation numbers after population expansion 


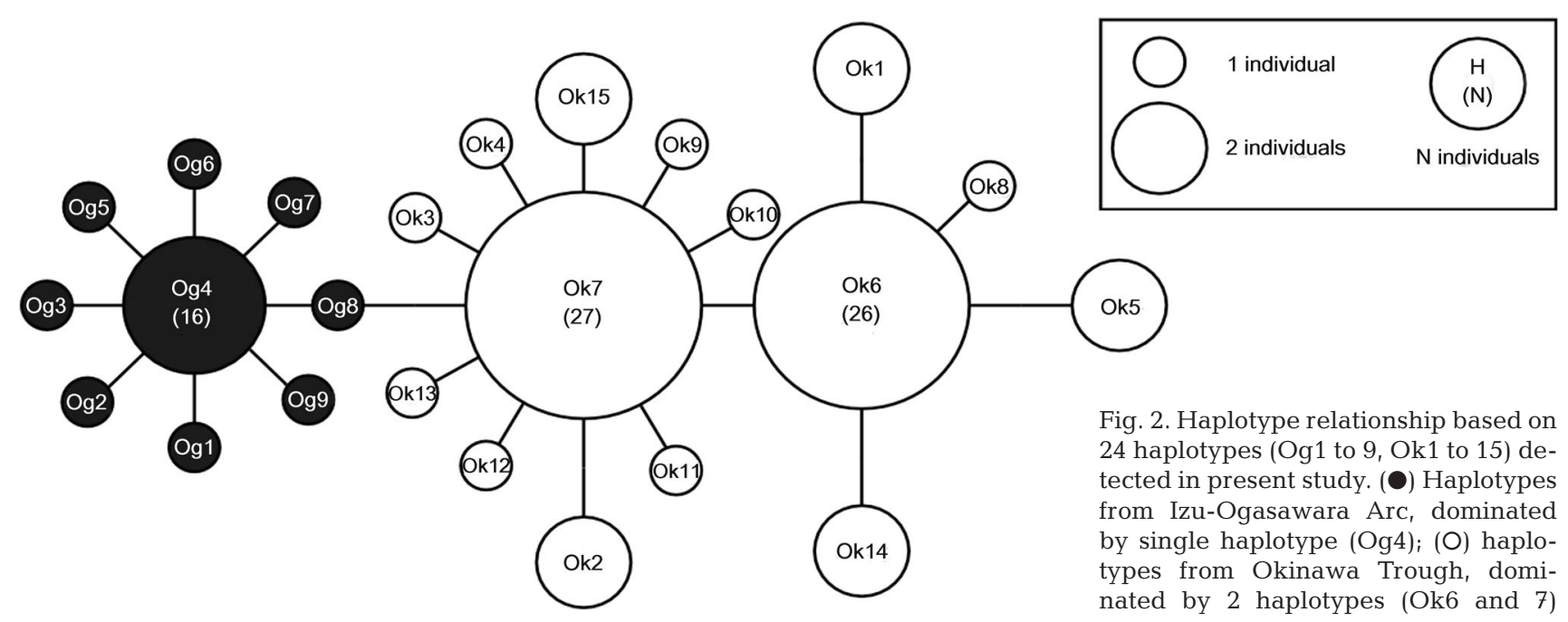

were estimated to be $21.5 \times 10^{3}$ (range from 0.0 to $33.6 \times$ $10^{4}, 99 \%$ confidence intervals) for the Izu-Ogasawara Arc, and $66.4 \times 10^{3}$ (range from $19.1 \times 10^{3}$ to $86.3 \times 10^{3}$, $99 \%$ confidence intervals) for the Okinawa Trough.

Molecular phylogenetic trees reconstructed with NJ and MP methods showed schematically the same

Table 2. Genetic diversity estimated for each neoverrucid population examined in the present study, and for the reference species the intertidal barnacle Balanus glandula (Wares et al. 2001), and the deep-sea verrucid barnacle Rostratoverruca krugeri. N: no. of individuals that were investigated in present study. H: no. of haplotypes detected, $\hat{H}$ : haplotype diversity; $\pi$ : nucleotide diversity

\begin{tabular}{|lrrcc|}
\hline Locality & $\mathrm{N}$ & $\mathrm{H}$ & $\hat{H} \pm \mathrm{SE}$ & $\pi \pm \mathrm{SE}$ \\
\hline Individual populations & & & & \\
Myo & 19 & 9 & $0.678 \pm 0.122$ & $0.0018 \pm 0.0013$ \\
Kai & 5 & 1 & $0.000 \pm 0.000$ & $0.0000 \pm 0.0000$ \\
Izn & 19 & 5 & $0.649 \pm 0.085$ & $0.0013 \pm 0.0011$ \\
Nih & 17 & 7 & $0.779 \pm 0.074$ & $0.0021 \pm 0.0015$ \\
Hat & 16 & 5 & $0.733 \pm 0.079$ & $0.0022 \pm 0.0016$ \\
Yon & 20 & 7 & $0.774 \pm 0.065$ & $0.0019 \pm 0.0014$ \\
Ali & 14 & 8 & $0.857 \pm 0.077$ & $0.0049 \pm 0.0032$ \\
Regional populations & & & & \\
Izu-Ogasawara Arc & 24 & 8 & $0.507 \pm 0.125$ & $0.0013 \pm 0.0010$ \\
Okinawa Trough & 58 & 14 & $0.717 \pm 0.042$ & $0.0017 \pm 0.0013$ \\
Reference species & & & & \\
Balanus glandula & 38 & & 0.966 & 0.0106 \\
Rostratoverruca krügeri & 7 & 7 & $1.000 \pm 0.076$ & $0.0064 \pm 0.0043$ \\
\hline
\end{tabular}

topology (Fig. 4). Neoverrucids collected from the IzuOgasawara Arc and the Okinawa Trough formed a monophyletic cluster, within which the haplotypes obtained from the Izu-Ogasawara Arc formed a monophyletic cluster. The haplotypes of the Okinawa Trough formed a paraphyletic cluster with the exclusion of a monophyletic cluster from the Izu-Ogasawara Arc.

The sequence divergences between haplotypes from the Izu-Ogasawara Arc and those from the Okinawa Trough were estimated using Kimura 2-parameter distance to be 0.007 to 0.015 . Using the mutation rate calculated by Knowlton \& Weigt (1998), the divergence time of the Japanese neoverrucids was estimated at less than 1 Myr ago.

\section{DISCUSSION}

\section{Genetic diversity of neoverrucids}

Compared with the intertidal barnacle Balanus glandula (Wares et al. 2001) and the deep-sea verrucid barnacle Rostratoverruca krügeri ( $\mathrm{H}$. Watanabe et al. unpubl. data), all the neoverrucid populations investigated in this study had low

Table 3. Results of AMOVA testing significance of neoverrucid population structure

\begin{tabular}{|lrrr|}
\hline & Variance & \% of variance & $\Phi$-statistics \\
\hline Among regional population & 0.1534 & 30.45 & 0.3045 \\
Among individual population within regional populations & -0.0064 & -1.27 & $<0.001$ \\
Within individual populations & 0.3569 & 70.83 & 0.0183 \\
\hline
\end{tabular}



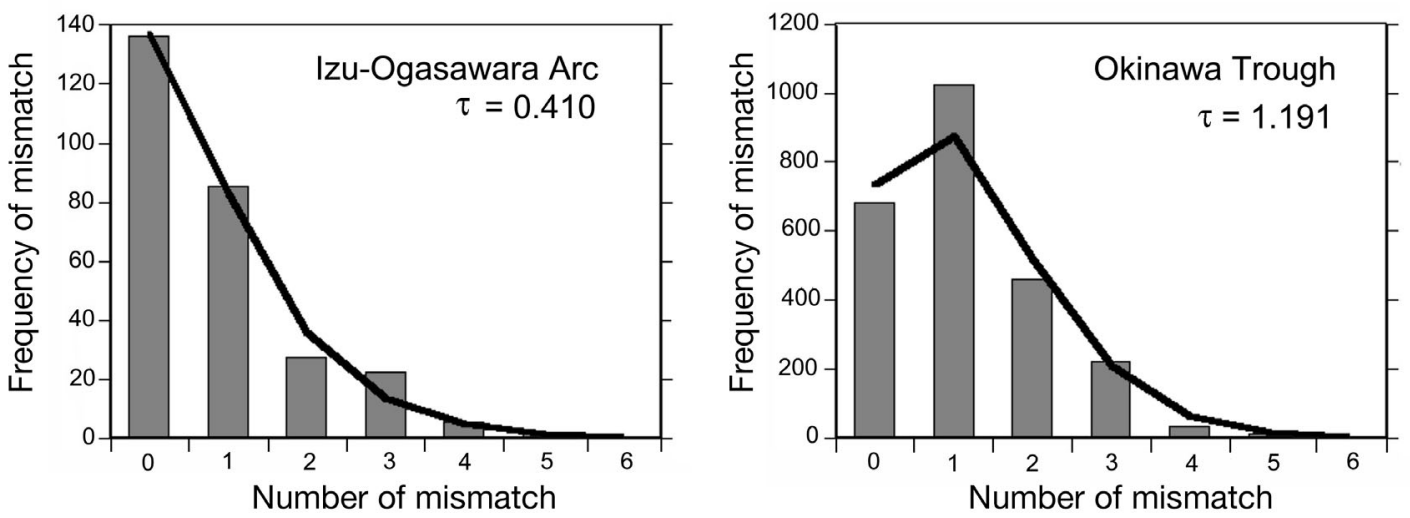

Fig. 3. Mismatch distribution of populations of Izu-Ogasawara Arc and Okinawa Trough. Line graph: expected distribution for sudden-expansion model; bar graph: observed distribution
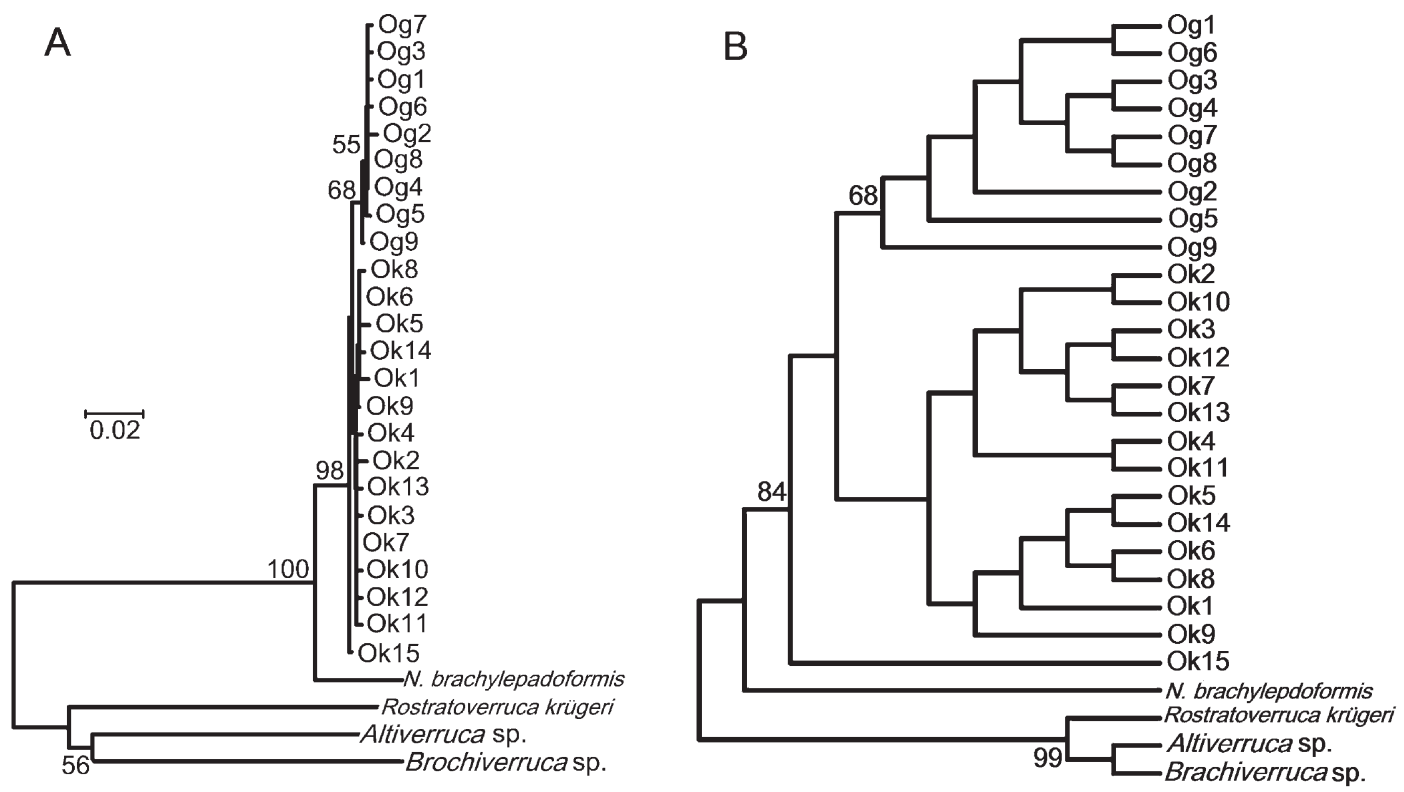

Fig. 4. Molecular phylogenetic trees reconstructed for 24 haplotypes from Japanese neoverrucids and Neoverruca brachylepadoformis from Mariana Trough using 3 verrucid species as an outgroup. Bootstrap values with 1000 replicates are shown beside branches supported by bootstrap values $>50 \%$. (A) Neighbor-joining (NJ) tree based on Kimura 2-parameter distance; (B) unweighted maximum-parsimony (MP) tree. MP analysis resulted in single most-parsimonious tree with 366 steps, a consistency index (CI) of 0.7678 , and a retention index (RI) of 0.7079

levels of genetic diversity (Table 2). In particular, low genetic diversities were observed for the Kaikata Seamount population. For vestimentiferan tubeworms, Kojima et al. (2002) suggested that vent-endemic species might have low genetic diversity due to the instability of their habitats. For the Izu-Ogasawara Arc, the lifetime of some hydrothermal vents are thought to be much shorter than those of the vents in the Mid Oceanic Ridge, according to geochemical studies (Ishibashi \& Urabe 1995). In addition, animal communities associated with the Kaikata Seamount vent field changed between 1996 and 2003, and the neoverrucid population has rapidly declined in numbers (Ohno et al. 1996, Tsuchida et al. 2001, Watanabe et al. 2003).
This continuing population contraction is thought to have decreased the genetic diversity of the population at the Kaikata Seamount. However, as only 5 specimens were examined from the Kaikata Seamount, their genetic diversity may be underestimated.

On the other hand, mismatch analyses that were carried out for the 2 regional populations (the IzuOgasawara Arc and the Okinawa Trough) suggested that each population has experienced sudden expansion (Fig. 3). According to Rogers \& Harpending (1992), the bottleneck effect may be distinguished from the sudden-expansion model by showing elevated upper-tail probability in mismatch distribution. Therefore, most of the present mismatch distributions of neo- 
verrucid populations were interpreted as suddenly expanded populations from newly colonizing small populations. The estimated generation number after population expansion for the Izu-Ogasawara Arc is $21.5 \times 10^{3}$ and that for the Okinawa Trough is $64.4 \times 10^{3}$. The generation time for vent barnacles is unknown. However, the time period of population expansion estimated from the mismatch analysis is much shorter than the histories of the Izu-Ogasawara Arc (17 Myr ago: Morita et al. 1999) and the Okinawa Trough (2 Myr ago: Furukawa 1991). Holm \& Hennet (1992) suggested that individual vent fields are probably active for several thousands of years, i.e. individual vent fields may have experienced severe population reduction, extinctionrecolonization or foundation by vent animals over long and large scales of vent activity in the Izu-Ogasawara Arc and the Okinawa Trough. The present results from the mismatch analysis suggest that the populations of the Izu-Ogasawara Arc and the Okinawa Trough have experienced extinction-recolonization events.

\section{Dispersal of neoverrucid larvae around Japan}

The results of the AMOVA (Table 3) and the exact test showed that there was no significant genetic subdivision within populations of the Izu-Ogasawara Arc and the Okinawa Trough and that no haplotypes were common between these 2 regions. Therefore, each of the 2 populations is regarded as panmictic, and gene flow occurs only within each region. As barnacles are sessile organisms, most gene flow is undoubtedly due to larval dispersal. Thus, the present results suggest that the larvae of neoverrucids disperse largely within the IzuOgasawara Arc and the Okinawa Trough, e.g. dispersal between the 2 regions must be very infrequent. Watanabe et al. (2004) showed that the planktonic larval period of Neoverruca sp. from the Dai-yon Yonaguni Knoll in the Okinawa Trough was $108 \mathrm{~d}$ on average through 6 lecithotrophic naupliar stages when reared under laboratory conditions $\left(4^{\circ} \mathrm{C}\right.$, atmospheric pressure). The bottom current speeds around the vent fields, measured during submersible observations, ranged from 0.05 to $0.25 \mathrm{~m} \mathrm{~s}^{-1}$ (unpubl. data in reports of Cruises NT00-12 and NT02-07 and 08 of the RV 'Natsushima'). Therefore, during the $108 \mathrm{~d}$ of the planktonic period, the larvae could be transported 470 to $2330 \mathrm{~km}$. The most distant vent fields within the Okinawa Trough (the Izena Hole and the Dai-yon Yonaguni Knoll) are approximately $800 \mathrm{~km}$ distant, whereas the nearest vent fields are less than $470 \mathrm{~km}$ away. Thus, the larvae could easily disperse within the Okinawa Trough. In contrast, in the Izu-Ogasawara Arc, the Myojin Knoll and the Kaikata Seamount are approximately $800 \mathrm{~km}$ apart and, as yet, no vent fields containing bar- nacles have been found between them. If there were direct currents slower than $0.09 \mathrm{~m} \mathrm{~s}^{-1}$, the larvae could not disperse between these 2 vent fields. On the other hand, as the distance between the Izu-Ogasawara Arc and the Okinawa Trough is 1500 to $2000 \mathrm{~km}$, neoverrucid larvae could disperse between them if the current speed was faster than $0.16 \mathrm{~m} \mathrm{~s}^{-1}$. The Kuroshio current is a strong warm-water current and the effects of its flow can reach a few thousands of meters below the sea surface. It flows through the East China Sea to the Izu-Ogasawara Islands and, presumably, the larvae of neoverrucids could be transported from the Okinawa Trough to the Izu-Ogasawara Arc by the effect of the Kuroshio. The current speed reachs 0.10 to $0.20 \mathrm{~m} \mathrm{~s}^{-1}$ at a depth range of 2000 to $3500 \mathrm{~m}$ below the Kuroshio (Fukazawa et al. 1985). The length of the planktonic period of neoverrucids and the current speed seems to be sufficient for dispersal of the larvae between the IzuOgasawara Arc and the Okinawa Trough. However, it is thought to be difficult for the larvae to disperse between the 2 regions because of the existence of the Ryukyu Arc, which is located between the IzuOgasawara Arc and the Okinawa Trough. When the main branch of the Kuroshio flows from the East China Sea, it must pass over the sill of the Ryukyu Arc at a depth of several hundred meters, where the seawater temperature directly above the sill reaches $15^{\circ} \mathrm{C}$ (Nitani 1972). To be transported by this current, the larvae would need to float or swim up from cold $\left(4\right.$ to $5^{\circ} \mathrm{C}$ near their habitat) and deep (at a depth approximately $1500 \mathrm{~m}$ ) water. However, in laboratory rearing experiments, the survival rate of neoverrucid larvae drastically decreased at temperatures higher than $15^{\circ} \mathrm{C}$ under atmospheric pressure (Kado et al. unpubl. data). Therefore it appears to be almost impossible for the larvae to disperse from the Okinawa Trough to the IzuOgasawara Arc via the Kuroshio. Most larvae probably remain in deeper water, where they help maintain the neoverrucid populations in the Okinawa Trough.

\section{History of Japanese neoverrucids}

The results of the present phylogenetic analysis show that Japanese neoverrucids form a monophyletic cluster, within which the haplotypes of the Okinawa Trough are paraphyletic, with the exclusion of a monophyletic group of haplotypes from the Izu-Ogasawara Arc (Fig. 4). The divergence date between the populations of the Izu-Ogasawara Arc and the Okinawa Trough was estimated to be more recent than $1 \mathrm{Myr}$ ago, namely, after the Middle Pleistocene. From the mismatch analysis, the estimated generation numbers after population expansion was shorter in the Okinawa Trough than of the Izu-Ogasawara Arc (Fig. 3). 
Ishibashi \& Urabe (1995) suggested that the activity of the Izu-Ogasawara Arc is periodic, and therefore the probability of the populations of the Izu-Ogasawara Arc having experienced extinction-recolonization events may be higher than for the Okinawa Trough populations. Furthermore, as discussed above, the Kuroshio current, which has existed since at least the Tertiary period, flows through the East China Sea to the IzuOgasawara Islands, and may have contributed to the transportation of neoverrucid larvae unidirectionally from the Okinawa Trough to the Izu-Ogasawara Arc during the cold periods when the water temperature directly above the sill formed by the Ryukyu Arc did not exceed $15^{\circ} \mathrm{C}$. Thus, it is most plausible that the population in the Okinawa Trough is the source population of the IzuOgasawara Arc population. In many animals, divergence of major lineages has been estimated to have occurred in the Late Tertiary and Quarternary, associated with climatic and tectonic changes (Avise 2000). There is a possibility that a divergence event in the neoverrucid populations in the Izu-Ogasawara Arc and the Okinawa Trough was caused by these changes, even though these populations inhabit deep-sea hydrothermal vent fields. Finally, since vent fields constitute an ephemeral and patchily distributed environment, there is a possibility that there are some undiscovered vent fields around Japan. Were any such to be discovered and molecular data of neoverrucids gathered, a more detailed larval dispersal and population history would be possible.

Acknowledgements. We are grateful to Professor T. Yamaguchi of Chiba University, as well as the onboard scientists of Cruises NT00-06, NT00-12, NT01-05, NT02-07 and 08, KY0211, NT03-06, NT03-09, the officers and crew of the RVs 'Natsushima' and 'Kaiyo' and the operation team of the submersible 'Shinkai 2000' and the ROV 'HyperDolphin' under operation managers Y. Yoda, H. Shibata and K. Mitsufuji. For collection of the verrucid barnacles, we appreciate the effort of the crews and officers of the RV 'Tansei-Maru', and especially of Ms. K. Suetsugu of ORI. We also thank Dr. R. Kado and members of the School of Fisheries Sciences of Kitasato University for provided unpublished data on Neoverruca larvae, and the Benthos laboratory of ORI and the Marine Ecosystem Research Group at JAMSTEC, especially Dr. D. J. Lindsay, for useful discussions. Part of this study was supported by grants from the Ministry of Education, Culture, Sports, Science and Technology of Japan (No. 12NP0201) and the Research Institute of Marine Invertebrates Foundation (Tokyo, Japan).

\section{LITERATURE CITED}

Avise JC (2000) Phylogeography, the history and formation of species. Harvard University Press, Cambridge, MA

Excoffier L, Smouse PE, Quattro JM (1992) Analysis of molecular variance inferred from metric distances among DNA haplotypes: application to human mitochondrial DNA restriction data. Genetics 131:479-491

Folmer O, Black M, Hoeh W, Lutz RA, Vrijenhoek RC (1994)
DNA primers for amplification of mitochondrial cytochrome c oxidase subunit I from diverse metazoan invertebrates. Mol Mar Biol Biotechnol 3:294-299

Fujikura K, Fujiwara Y, Ishibashi J, Katayama S and 16 others (2001) Report on investigation of hydrothermal vent ecosystems by the crewed submersible 'Shinkai 2000' on the Dai-yon (No. 4) Yonaguni Knoll and the Hatoma Knoll, the Okinawa Trough. JAMSTEC J Deep Sea Res 19:141-154 (in Japanese text with English abstract, tables and figures)

Fukazawa O, Teramoto T, Taira K, Kawabe M and 5 others (1985) The Kuroshio Current in the Shikoku Basin. In: Kajiura K (ed) Oceanic characteristics and their changes. Kouseisha-Kouseikaku, Tokyo, p 89-120 (in Japanese)

Furukawa M (1991) Formation age of the Ryukyu Arc-Okinawa Trough system. J Geogr Tokyo 100:552-564 (in Japanese text with English abstract, tables and figures)

Holm NG, Hennet RJC (1992) Hydrothermal systems: their varieties, dynamics, and suitability for prebiotic chemistry. In: Holm NG (ed) Marine hydrothermal systems and the origin of life. Kluwer Academic Publishers, Dordrecht, p 15-31

Iizasa K, Fiske RS, Ishizuka O, Yuasa M and 7 others (1999) A Kuroko-type sulfide deposit in a submarine silicic caldera. Science 283:975-977

Ishibashi J, Urabe T (1995) Hydrothermal activity related to Arc-Backarc magmatism in the Western Pacific. Backarc Basins. In: Taylor B (ed) Tectonics and magmatism. Plenum Press, New York, p 451-495

Knowlton N, Weigt LA (1998) New dates and new rates for divergence across the Isthmus of Panama. Proc R Soc Lond B 265:2257-2263

Kojima S (2002) Deep-sea chemosynthesis-based communities in the Northwestern Pacific. J Oceanogr 58:343-363

Kojima S, Ohta S, Yamamoto T, Miura T, Fujiwara Y, Fujikura K, Hashimoto J (2002) Molecular taxonomy of vestimentiferans of the western Pacific and their phylogenetic relationship to species of the eastern Pacific. II. Families Escarpiidae and Arcovestiidae. Mar Biol 141:57-64

Kumar S, Tamura K, Jakobsen IB, Nei M (2001) Molecular evolutionary genetics analysis Version 2.1. Institute of Molecular Evolutionary Genetics, Pennsylvania State University, University Park, PA

Morita S, Ishizuka O, Hochstaedter A, Ishii T, Yamamoto F, Tokuyama E, Taira A (1999) Volcanic and structural evolution of the Northern Izu-Bonin Arc. Monthly Chikyu (Suppl) 23:79-88 (in Japanese)

Newman WA (1985) The abyssal hydrothermal vent invertebrate fauna: a glimpse of antiquity? Bull Biol Soc Wash 6: 231-242

Newman WA (2000) A new genus and species of barnacle (Cirripedia, Verrucomorpha) associated with vents of the Lau Back-Arc Basin: its gross morphology, inferred first juvenile stage and affinities. Zoosystema 22:71-84

Newman WA, Hessler RR (1989) A new abyssal hydrothermal verrucomorpha (Cirripedia; Sessilia): the most primitive living sessile barnacle. Trans S Diego Soc Nat Hist 21: 256-273

Nitani H (1972) Beginning of the Kuroshio. In: Stommel H, Yoshida K (eds) Kuroshio, its physical aspects. University of Tokyo Press, Tokyo, p 129-164

Ohno T, Fujikura K, Hashimoto J, Fujiwara Y, Segawa S (1996) The hydrothermal vent community at the Kaikata Seamount near Ogasawara (Bonin) Islands, South Japan. JAMSTEC J Deep Sea Res 12:221-229 (Japanese text with English abstract, tables and figures)

Okutani T, Fujiwara Y (2000) Gastropod fauna of a thermal vent site on the north knoll of Iheya Ridge, Okinawa 
Trough. Venus Jpn J Malacol 59:123-128

Raymond M, Rousset F (1995) An exact test for population differentiation. Evolution 49:1280-1283

Rogers AR, Harpending H (1992) Population growth makes waves in the distribution of pairwise genetic differences. Mol Biol Evol 9:552-569

Schneider S, Excoffier L (1999) Estimation of past demographic parameters from the distribution of pairwise differences when the mutation rates vary among sites: application to human mitochondrial DNA. Genetics 152: 1079-1089

Schneider S, Roessli D, Excoffier L (2000) ARLEQUIN, a software for population genetics data analysis. Genetics and Biometry Laboratory, Department of Anthropology, University of Geneva

Tsuchida S, Kumagai H, Ishibashi J, Watanabe H, Kouduma F (2001) Preliminary report of hydrothermalism and volcanism at the Kaikata Seamount. JAMSTEC J Deep Sea Res

Editorial responsibility: Otto Kinne (Editor-in-Chief), Oldendorf/Luhe, Germany
18:209-215 (Japanese text with English abstract, tables and figures)

Tunnicliffe V, Fowler CMR (1996) Influence of sea-floor spreading on the global hydrothermal vent fauna. Nature 397:531-533

Wares JP, Gaines SD, Cunningham CW (2001) A comparative study of asymmetric migration events across a marine biogeographic boundary. Evolution 55:295-306

Watanabe H, Kado R, Tsuchida S, Kano Y and 7 others (2003) Dispersion and reproduction of vent-endemic species inhabiting the Myojin Knoll and the Kaikata Seamount. Preliminary report of NT03-06, Leg 2 cruise. JAMSTEC J Deep Sea Res 23:99-105 (Japanese text with English abstract, tables and figures)

Watanabe H, Kado R, Tsuchida S, Miyake H, Kyo M, Kojima S (2004) Larval development and intermoult period of the hydrothermal vent barnacle Neoverruca sp. J Mar Biol Assoc UK 84:743-745

Submitted: June 3, 2004; Accepted: December 7, 2004 Proofs received from author(s): February 7, 2005 